
ARQUEOLÓGICOS EM RESERVATÓRIOS DE HIDRELÉTRICAS JÁ INSTALADAS PROPOSAL OF A GROUND PROTOCOL FOR ARCHAEOLOGICAL MONITORING IN HYDROELECTRIC RESERVOIRS ALREADY INSTALLED 


\title{
Proposta de protocolo de gradeamento para monitoramentos arqueológicos em reservatórios de hidrelétricas já instaladas
}

\author{
Manoella de Souza Soares ${ }^{1}$
}

\begin{abstract}
Resumo: O presente artigo tem por objetivo apresentar a proposta de protocolo de gradeamento para monitoramento arqueológico em reservatórios hidrelétricos. Este é parte constituinte da dissertação de mestrado da autora, em desenvolvimento na UHE Capivari-Cachoeira localizada nos municípios de Campina Grande do Sul e Bocaiuva - Paraná. Além de estabelecer um protocolo o presente artigo visa compartilhar a experiência realizada e as reflexões que constituíram a escolha por esta técnica analítica. Visando abranger as necessidades metodológicas que o monitoramento arqueológico em reservatórios já instalados em gerando, bem como a compreensão de relações entre empreendimentos deste porte com sítios arqueológicos localizados às margens. Baseado em trabalhos similares realizados no hemisfério norte, a presente pesquisa propõe a realização de estudo semelhante em ambiente tropical-subtropical, onde a influência de elementos como o gelo é desconsiderado e a erosão por precipitação possui regime diferenciado.
\end{abstract}

Palavras-chave: Transporte de Artefatos; Monitoramento Arqueológico; Experimentação.

\begin{abstract}
The present article aims to present a proposal of classification protocol for laboratory monitoring in hydroelectric reservoirs. This is a constituent part of the author's master's thesis, under development at the UHE-Capivari-Cachoeira located in the municipalities of Campina Grande do Sul and Bocaiuva - Paraná. In addition to establishing a protocol or present article, consider the experience performed as reflections that constitute a choice for this analytical technique. Aiming to cover as methodological needs that the monitoring of vessels in reservoirs already installed in generating, as well as an understanding of relationships between ventures of this size with archaeological sites located at the margins. Based on successful works, without a northern hemisphere, a present study research in tropical-subtropical environment, where an influence of elements such as ice and inconsiderate and a precipitation erosion has a different regime.
\end{abstract}

Keywords: Transport of Artifacts; Archaeological Monitoring; Experimentation.

\section{INTRODUÇÃO}

Originado a partir das reflexões e necessidades metodológicas da dissertação de mestrado da presente autora, este artigo tem por objetivo propor um protocolo de monitoramento arqueológico para margens de reservatórios já instalados. A fim de compreender as inter-relações reservatório $X$ margens $X$ ocorrência arqueológica mostrou-se necessária a mensuração de possíveis movimentações de materiais arqueológicos. A variação do nível do reservatório, a ação das ondas nas margens, a formação de pequenas drenagens de ordem zero em momentos de precipitação, entre outros são possíveis agentes para a alteração do registro arqueológicos. Para tal, é proposta a instalação de grades, georreferenciadas, instaladas em áreas com ocorrências arqueológicas e/ou áreas estratégicas com a utilização de pseudo-artefatos, objetivando a identificação de deslocamentos e/ou soterramento.

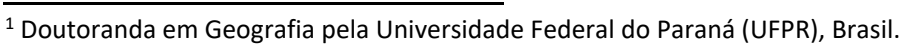


O monitoramento é uma atividade que requer tempo de coleta de dados e procedimentos que possibilitem futuras análises, por exemplo, correlacionando com dados de laboratório. Neste artigo serão apresentados os procedimentos adotados para a delimitação das áreas de monitoramento, a metodologia de gradeamento e as primeiras discussões sobre a necessidade de monitorar margens de reservatórios, objetivando os estudos geoarqueológicos.

A escolha pelo gradeamento surgiu da leitura do trabalho de WILL e Clark (1996), que realizou experimento similar nas margens de um lago no Maine - EUA. A pesquisa lá realizada possui a especificidade de estar localizado em clima ártico, o que faz com que o gelo seja agente com grande atuação sobre os artefatos. Até o presente momento não foi identificado outro trabalho similar para climas tropicais e subtropicais, por isso a necessidade da produção de tal protocolo.

Para o estabelecimento de tal protocolo será aqui apresentada à experiência realizada no reservatório da UHE Capivari-Cachoeira, localizado entre os municípios de Campina Grande do Sul e Bocaiuva no Estado do Paraná (Figura 01). O reservatório foi totalmente preenchido em 1970, e por ser anterior as leis ambientais vigentes, não foram realizados estudos arqueológicos. Em 2000 foram realizados monitoramentos devido a redução do nível do reservatório que resultou na dissertação de mestrado de Rucirene Miguel (2000), cujo título é: "Estudos de processos erosivo-acumulativos em ocorrências arqueológicas impactadas por reservatório: UHE Capivari-Cachoeira".

\section{MONITORAMENTO ARQUEOLÓGICO}

O monitoramento arqueológico, como instrumento para o licenciamento ambiental, está intrinsecamente associado ao monitoramento ambiental. Desta forma e em virtude dos poucos trabalhos relacionados diretamente à definição do monitoramento arqueológico, este será aqui trado de forma transdisciplinar com as noções de monitoramento ambiental, instituído pelo Instituto Brasileiro de Meio Ambiente e dos Recursos Naturais Renováveis (IBAMA), bem como o de monitoramento florestal, baseados primordialmente no trabalho desenvolvido por Rodriguez (1998).

Para o IBAMA, monitoramento é o ato de estudar e acompanhar, de forma continua e sistemática, o comportamento de eventos, situações e fenômenos específicos, com o objetivo de identificar, avaliar e comparar um dado indicador. O conceito e a necessidade de caracterizar indicadores no processo de monitoramento são marcantes nas diversas concepções de monitoramento.

$\mathrm{Na}$ tentativa de uma aproximação desta definição com a realidade do monitoramento arqueológico, este seria o estudo e o acompanhamento da ausência dos indicadores arqueológicos. Estes indicadores seriam essencialmente vestígios diretos e indiretos, seja um fragmento cerâmico seja à marca negativa de uma fogueira, por exemplo. Diferente do monitoramento ambiental, que utiliza da presença de 
dados indicadores para evidenciar a evolução dos processos degradantes, e constatar os impactos nos recursos naturais, o monitoramento arqueólogo utiliza a ausência dos indicadores para assegurar a falta de dano ao patrimônio arqueológico. Ou no presente caso, no qual o dano já está instaurado; já ocorreu a instalação do reservatório e este já atuou no registro arqueológico. O indicador para análise é o possível deslocamento dos artefatos, durante o processo de erosão das margens do reservatório.
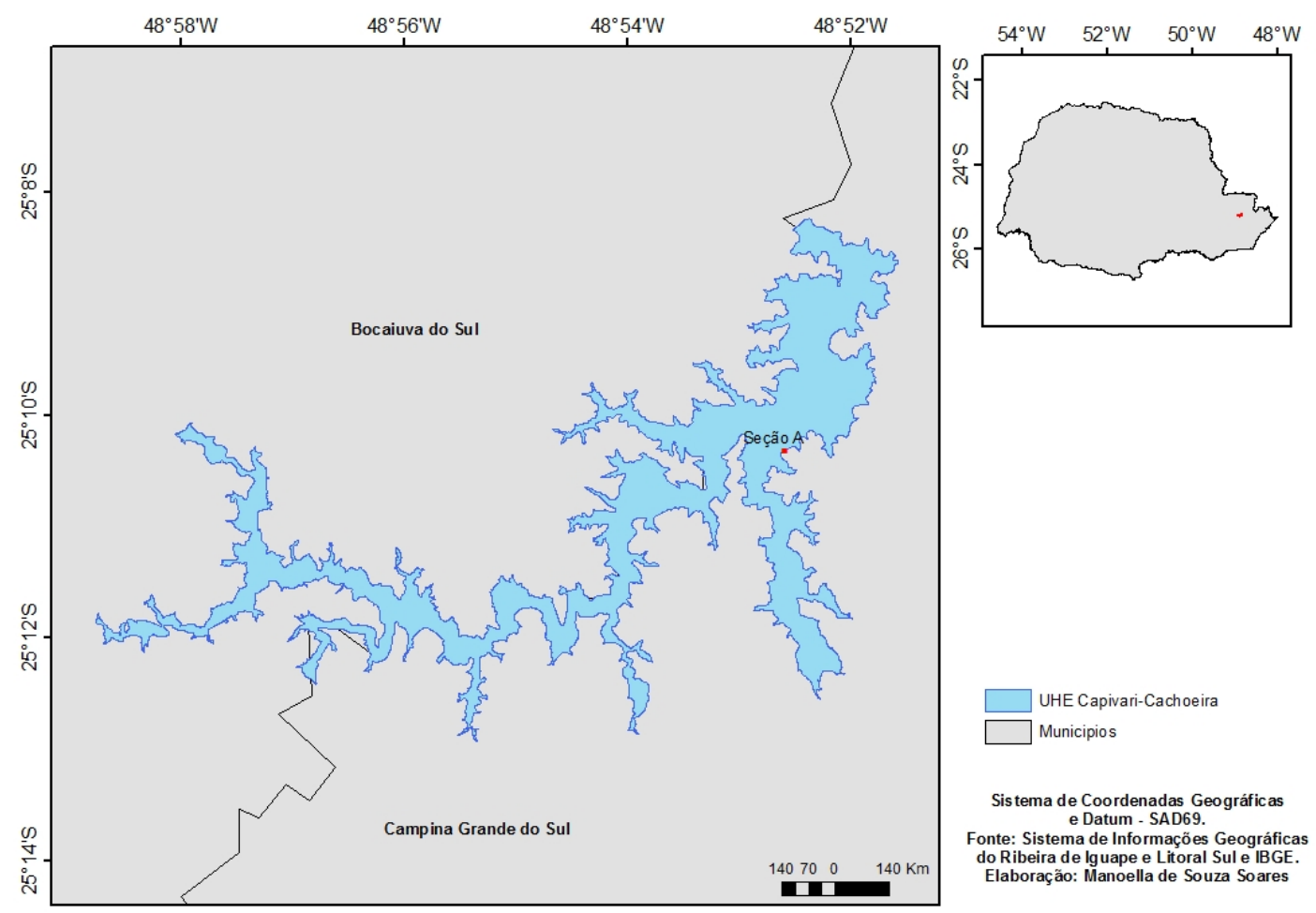

Figura 01: Mapa de localização do reservatório da UHE Capivari-Cachoeira/PR

Tratadas na obra de Rodriguez (1998), referentes ao monitoramento florestal, algumas questões básicas ao processo de monitoramento podem ser apropriadas a noção de monitoramento arqueológico, são elas:

Quais serão os propósitos, a intensidade e a frequência do monitoramento?

Como serão amostradas e coletadas as informações?

Como serão analisados os dados?

Como serão interpretados os resultados?

Como reconhecer se os objetivos do monitoramento estão sendo alcançados?

Dentre tais aspectos o presente artigo compreende o referente ao método de amostragem e coleta de informações; propondo uma grade georrefenciada para aferição da movimentação dos materiais. 


\section{O MONITORAMENTO ARQUEOLÓGICO EM RESERVATÓRIOS HIDRELÉTRICOS.}

O monitoramento arqueológico em reservatórios hidrelétricos anteriores a resolução CONAMA 001/86 é previsto na Portaria IPHAN nํ28/2003, e prevê a execução de projetos de levantamento, prospeç̧ão, resgate e salvamento na faixa de depleção ${ }^{2}$. Seu objetivo é suprir a carência de informações sobre sítios já impactos. A compreensão dos mecanismos de interação entre sítios arqueológicos e reservatório poderá auxiliar na tomada de decisão de resgate, salvamento e monitoramento de novos empreendimentos, no conhecimento da formação e/ou alteração de informações contidas na área dos sítios, e auxiliar no processo de gestão do uso das margens dos reservatórios, em conformidade com a Lei 9433/97 que prevê o uso múltiplo dos recursos hídricos, quando a existência de sítios arqueológicos identificados.

Estudos com enfoque no impacto de movimentação de artefatos sob ação do lago do reservatório são relativamente raros. Entretanto destacam-se os trabalhos realizados por Kashimoto (2007 e 2015), na região do alto Paraná, nos quais o monitoramento continuo evidenciou os recuos das margens e o impacto sob o patrimônio arqueológico, sendo relevante para esta pesquisa os relacionados ao arraste de material por erosão laminar. E Faccio (2015), com estudo realizado no Estado de São Paulo, no qual o autor identificou fragmentos de vasilhas cerâmicas com descolamento de $300 \mathrm{~m}$ de distância do contexto de deposição, após retrabalho dos fluxos de água.

Aspectos qualitativos da implantação de reservatórios em áreas de potencial arqueológico vêm sendo trabalhados como, a perda de informações pelo alagamento de sítios, destruição de estruturas arqueológicas para a construção das edificações e caminhos do complexo hidroenergético. O presente artigo visa ampliar a instrumentalização de informações quantitativas dos impactos desses empreendimentos.

O preenchimento do reservatório altera inicialmente o nível de base, modificando a dissecação do relevo, e assim apresentando um primeiro aspecto de alteração em sítios antes localizados em meia encosta, por exemplo. Com o preenchimento completo do reservatório outros agentes começam a atuar como o impacto das ondas geradas por este corpo d'água e a variação do nível, proporcionando uma oscilação vertical, de subida e descida da água (Figuras 2 e 3). Esta oscilação do nível mesmo que não possua energia cinética suficiente para o deslocamento de artefatos, faz com que os materiais passem por alterações de períodos submersos e aflorantes muito curtos, o que em especial para materiais argilosos auxilia na desagregação. Outro aspecto é que mesmo variações, razoavelmente pequenas, na ordem dos centímetros pode na topografia representar um porcentual de exposição significativo para um sitio arqueológico.

\footnotetext{
${ }^{2}$ Faixa de depleção: faixa na margem de reservatórios formada pela variação do nível do mesmo.
} 


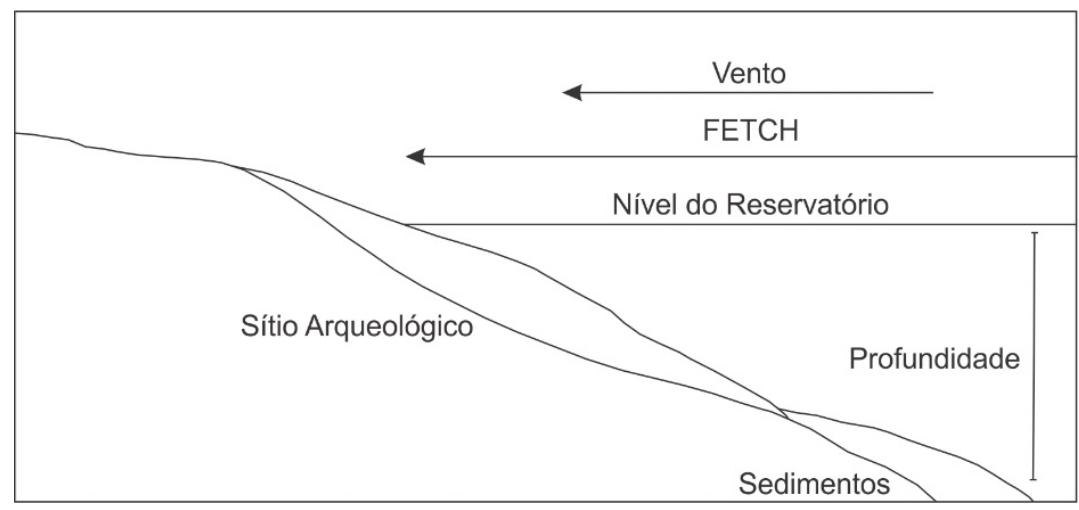

Figura 02: Esquema teórico da formação da onda em reservatório hidrelétrico e da definição de Fetch. Fonte: SOARES, 2015.

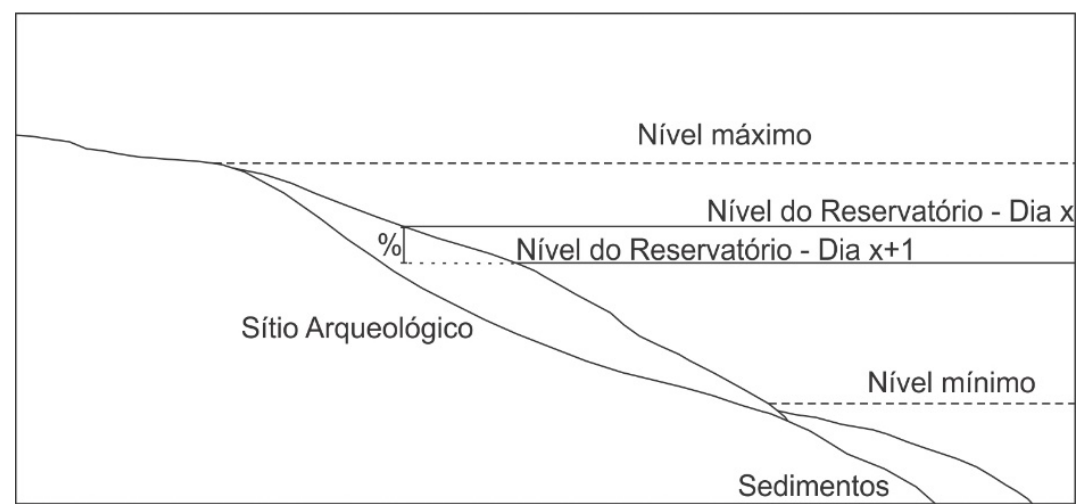

Figura 03: Esquema teórico da ação da variação do nível do reservatório sob o registro arqueológico localizado na margem. Fonte: SOARES, 2015.

\section{MATERIAIS E MÉTODOS}

Nos estudos relacionados à erosão é comum o uso de estações totais para levantamento topográfico dos perfis analisados, bem como a implantação de pinos de metal, para observação da remoção de sedimentos. A proposta aqui é de unir o levantamento topográfico com as informações das taxas de erosão em um dado perfil, para observar a movimentação de artefatos em diferentes partes da faixa de depleção.

A compreensão da movimentação de sedimentos é usualmente simplificada, em virtude dos muitos agentes envolvidos no processo de deslocamento. A interação da forma do material, densidade, atrito, forças atuantes faz com que muitos pesquisadores simplifiquem alguns elementos, por exemplo, consideram os sedimentos como esferas perfeitas. Porem quando falamos de artefatos arqueológicos, dificilmente este terá a forma esférica, a diversidade de cacos de cerâmica, de artefatos líticos ou mesmo de matérias formadores dos registros arqueológicos dificulta o uso dos métodos de transporte de sedimento.

Desta forma há a necessidade de estudos empíricos dos movimentos de artefatos, para compreensão de como esse fenômeno se dá e de que forma podemos explicar fisicamente seu 
comportamento. Este trabalho é a primeira fase de um estudo maior, objetivando identificar possíveis movimentos de materiais e de que forma esse movimento se dá.

\section{Preparação dos pseudo-artefatos}

A escolha dos materiais para o monitoramento partiu da disponibilidade de materiais similares aos artefatos encontrados na região. Para tal foram utilizados pedaços de lascas de rochas, fragmentos de cerâmica contemporânea e fragmentos de ossos e conchas. Este material foi catalogado e registrado com uma identificação especifica do projeto.

Foram registradas também as características físicas do pseudo-artefatos, como dimensões e peso, com objetivo de futuramente compreender a forma como tais materiais se movimentaram. Como foi colocado anteriormente, nos estudos de transporte de sedimentos simplificações são realizadas, entre elas a aproximação dos sedimentos a esferas. Para tal coeficientes de formas são utilizados como a esfericidade e o shape factor, que comparam a área do material à área de uma esfera (Tabela 1).

\section{Área de experimentação}

Empreendimentos hidrelétricos com represamento possuem o diferencial da formação de lagos artificiais. Além do impacto gerado pela submersão e soterramento de sítios, a interação entre este novo corpo d'água e as margem podem por sua vez gerar efeitos no registro arqueológico ali localizado. Um dos principais efeitos gerados pela formação do lago é a possibilidade formação de ondas, diferentemente de rios, onde o escoamento é o principal agente erosivo.

Segundo Fendrich (1993, p. 1), podemos compreender a onda como o movimento das águas superficiais resultante das forças tangenciais entre vento e água, bem como da diferença de pressão atmosférica sobre a superfície do reservatório. Em águas interiores como lagos e reservatórios, a área relativamente pequena, quando comparadas com mares e oceanos, faz com que o comprimento do Fetch, pista de água onde incide o vento, seja limitador na formação de ondas nesses corpos d'água. Sendo assim a hipótese aqui adotada é a de que áreas de Fetch máximo seriam, por conseguintes áreas atingidas pelas ondas com maior potencial erosivo. Para tal é compreendido que a onda possui dois importantes papeis no processo erosivo: (I) a desagregação do solo localizado na margem do reservatório, e (II) e o transporte de sedimentos.

Desta forma foi utilizado o modelo computacional ONDACAD (MARQUES, 2013), para a geração de mapas de Fetch do reservatório da UHE Capivari-Cachoeira, entre os municípios de Campina Grande do Sul e Bocaiuva - PR. A partir desses mapas é possível identificar os locais nas margens do reservatório onde ocorrem os maiores valores de Fetch. Informações adicionais como a frequência e a intensidade dos ventos auxiliam a compreender e definir as áreas potenciais para as demais análises a serem realizadas. Para o 
Estado do Paraná foi desenvolvido estudo sobre o potencial eólico pelo Instituto de Tecnologia para o Desenvolvimento - LACTEC (2007), no qual tais informações estão facilmente apresentadas em mapas e gráficos. Sendo assim a primeira área de gradeamento foi estabelecida na área sobre incidência de ventos com maior intensidade SWS e onde segundo o mapa de Fetch apresenta maior pista de vento (Figura 4).

A instalação do experimento se deu com a colocação de pinos de ferro no solo, demarcando assim a área do gradeamento para futuras coletas de dados. Os materiais foram colocados na superfície da margem, de forma aleatória, procurando apenas não concentrar materiais de mesma natureza muito próximos, ou seja, eliminando concentrações de líticos, e conchas que poderiam influenciar os dados pela mudança de fluxo ao redor do artefato. Cada pseudo-artefato foi registrado com estação total (Figuras 5 a 7).

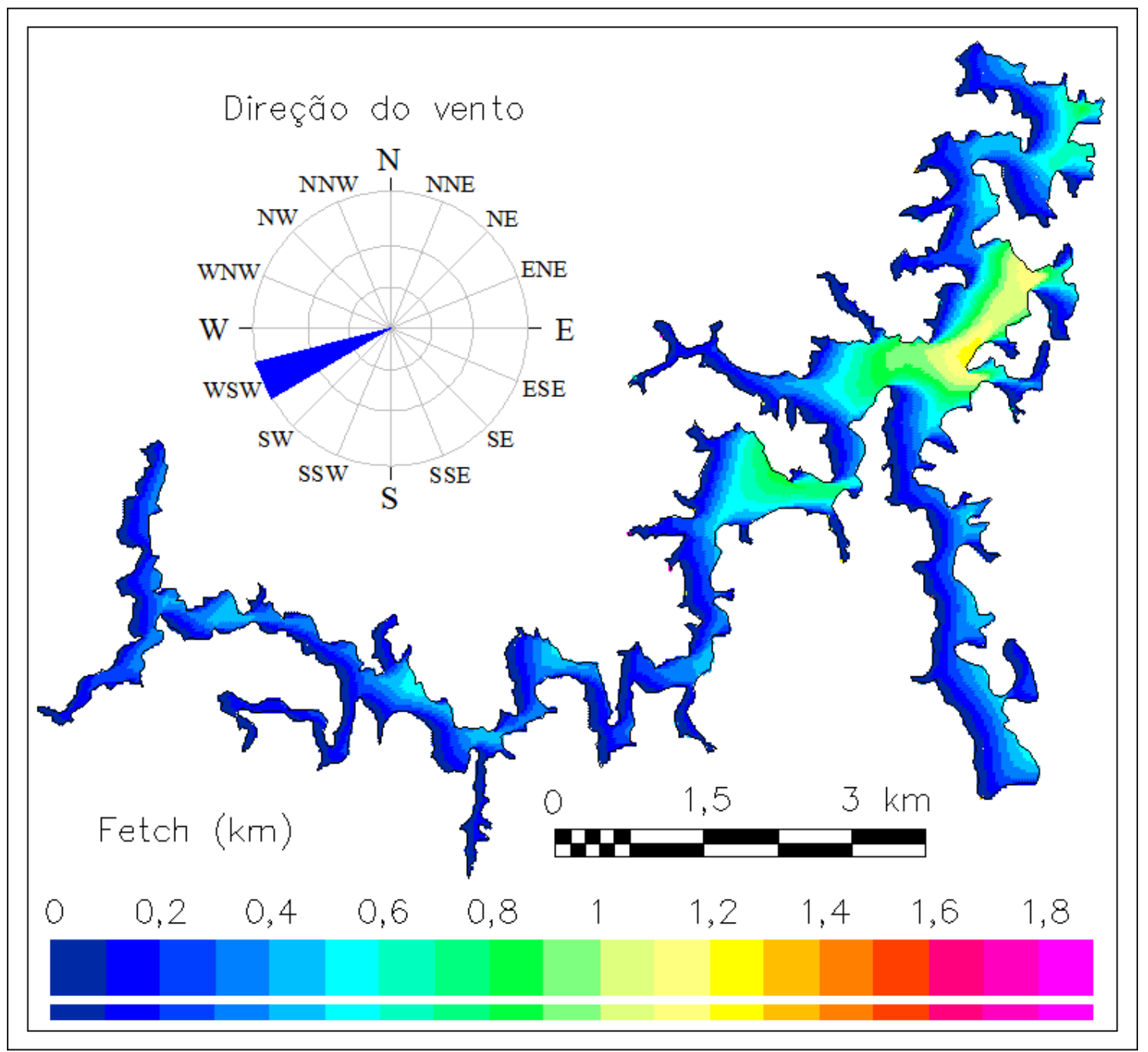

Figura 04: Mapa de distribuição de Fetch para o reservatório da UHE Capivari-Cachoeira, com ventos no sentido WSW. Fonte: SOARES, 2015. 


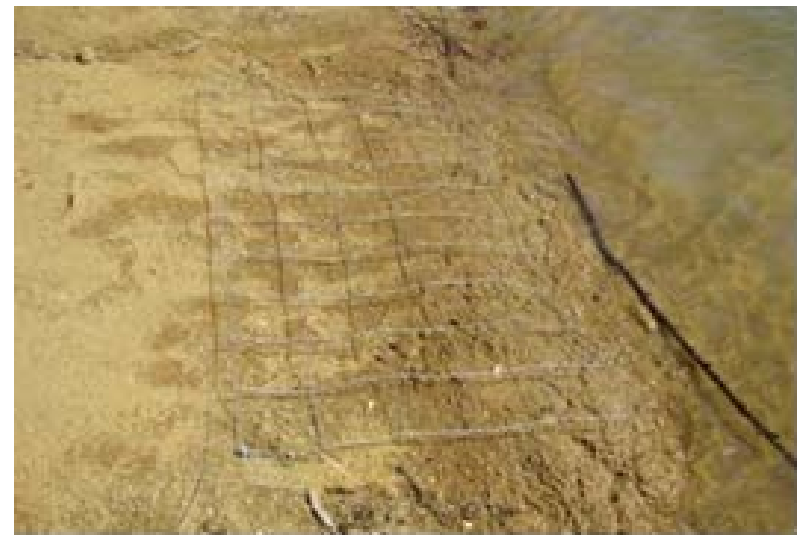

Figura 05: Colocação dos pinos de controle de gradeamento na margem do reservatório, foto retirada no sentido sul. Fonte: SOARES, 2015.

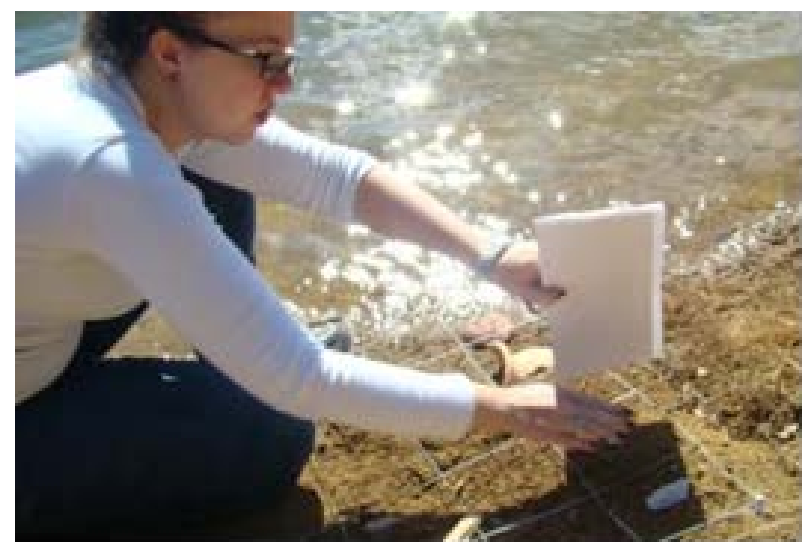

Figura06: Colocação dos pseudo artefatos no gradeamento e registro com estação total do posicionamento dos mesmos. Fonte: SOARES, 2015.

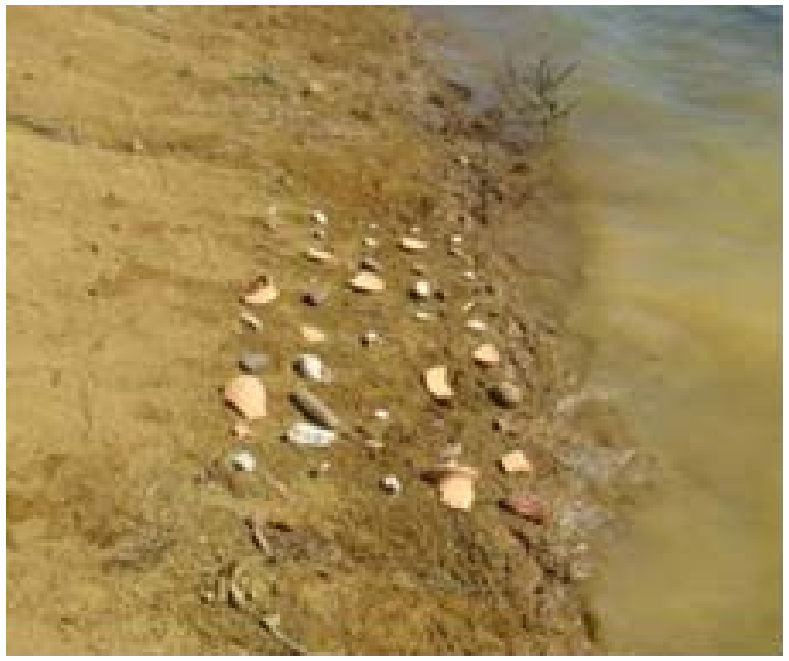

Figura 07: Distribuição dos pseudo artefatos no gradeamento as margens do reservatório já sem a grade de controle, foto retirada no sentido sul. Fonte: SOARES, 2015.

No momento da instalação do experimento não foi considerado a orientação dos eixos dos artefatos em relação a margem, o que influencia a mecânica de ação da água, especialmente nos movimentos ondulatórios, para geração de força de deslocamento deste. A presença do artefato, e sua posição em relação ao sentido da água, modificam em microescala as direções do fluxo, influenciando no resultado final das 
forças que geram a movimentação. As análises destas correlações se deram posteriormente, a partir da compreensão das movimentações e dos processos envolvidos, é aconselhável que futuras instalações considerem este fator. Para fins de discussão será adota a classificação de Zingg (1935), que considera a relação entre os três principais eixos (maior, médio e menor), e apresenta correlação com as questões hidrodinâmicas mencionadas acima. A Classificação de Zingg (1935), consiste nas relações entre os 3 diâmetros principais; a - eixo maior, b - eixo intermédio, e c-eixo menor; e pelas proporções entre c/b (p) e b/a (q). O grupo discoidal apresenta $p<0,6$ e q $>0,6$; esferoidal $p$ e $q>0,6$; lamelar $p$ e $q<0,6$; e por fim acicular $\mathrm{p}>0,6$ e $\mathrm{q}<0,6$.

\section{RESULTADOS E DISCUSSÕES}

Os resultados obtidos pela presente pesquisa demonstram que os processos associados à variação do nível da água na faixa de depleção de reservatórios hidrelétricos possuem elevado potencial de destruição e descaracterização de registros arqueológicos. Seja pelos processos erosivos que retiram camadas de material, com informações dos contextos arqueológicos, seja pelo próprio deslocamento de artefatos arqueológicos. Assim, estudos que estabeleçam modelos preditivos de impacto de empreendimentos deste tipo aos registros arqueológicos se fazem de extrema importância e são um relevante campo de pesquisa para a Geoarqueologia brasileira.

O uso do conceito de campo de Fetch para a compreensão de processos que envolvam ondas de corpos interiores, como reservatórios hidrelétricos, foi de grande utilidade neste trabalho. A facilidade de acesso deste tipo de informação, em que um parâmetro físico da onda, que não necessita a utilização de equipamentos sofisticados ou monitoramento, a usuários não especializados em processos hidrodinâmicos por trás das ondas, possibilitará o avanço de pesquisas em outras áreas, em especial aqui tratadas a geografia e a arqueologia. A compreensão do papel dos processos desencadeados pela formação de ondas e sua quantificação, ainda que parcial, pode auxiliar estudos em outras áreas.

No histórico de operação do reservatório a cota em que o gradeamento foi instalado, permanece 73\% do tempo submersa, o que indica que em momentos futuros será possível a avaliação do experimento em novas circunstâncias de influência do reservatório. No perfil em que o gradeamento foi instalado, foi obtido historicamente um volume erodido total de $11,10 \mathrm{~m}^{3}$, sendo que para a cota $840 \mathrm{~m}$, onde localiza-se o experimento, concentra-se $5,8 \%$ do volume total erodido do perfil.

No entanto, desde a instalação do gradeamento em 13 de junho de 2014, o experimento com artefatos permaneceu submerso apenas nos primeiros três dias, ficando o restante do período sem influência direta do nível do reservatório, o qual encontra-se em patamar inferior (cota $828 \mathrm{~m}$ ). No levantamento realizado no dia 26 de agosto de 2014 a maior parte dos materiais havia sido movimentada, seis conchas não 
PROPOSTA DE PROTOCOLO DE GRADEAMENTO PARA MONITORAMENTOS ARQUEOLÓGICOS EM RESERVATÓRIOS DE HIDRELÉTRICAS JÁ INSTALADAS

foram identificadas, sua baixa densidade e forma que propiciam o deslocamento, modificação sua posição em relação ao experimento de como que não foi possível sua localização (Figura 8 e 9 e Tabela 01).

Tabela 01: Movimentação dos pseudo artefatos no gradeamento da Seção A da UHE Capivari-Cachoeira. Fonte: Elaborado pela autora com base em Soares (2015). Acic - Acicular; Lam - Lamelar; Disc -

Discoidal; Esf - Esferoidal.

\begin{tabular}{|c|c|c|c|c|c|c|c|c|c|c|}
\hline \multirow{2}{*}{$\begin{array}{c}\text { Posição } \\
\text { na } \\
\text { grade }\end{array}$} & \multirow[t]{2}{*}{ ID } & \multirow[t]{2}{*}{ Tipo } & \multicolumn{3}{|c|}{ Medidas (cm) } & \multirow{2}{*}{$\begin{array}{l}\text { Peso } \\
\text { (gr) }\end{array}$} & \multirow{2}{*}{$\begin{array}{l}\text { Shape } \\
\text { Factor }\end{array}$} & \multirow{2}{*}{$\begin{array}{l}\text { Zingg } \\
\text { (1935) }\end{array}$} & \multirow[t]{2}{*}{ Movimento } & \multirow{2}{*}{$\begin{array}{l}\text { Direção do } \\
\text { Movimento }\end{array}$} \\
\hline & & & A & b & c & & & & & \\
\hline 1 & CCA42 & Lítico & 5,672 & 4,899 & 2,064 & 52,3 & 0,39 & Disc. & \multicolumn{2}{|c|}{ Sem movimento } \\
\hline 2 & CCA59 & Vidro & 2,784 & 2,31 & 0,915 & 6,4 & 0,36 & Disc. & $4,85 \mathrm{~cm}$ & \\
\hline 3 & CCA66 & Osso & 4,152 & 3,224 & 1,898 & 9,8 & 0,51 & Disc. & $12,46 \mathrm{~cm}$ & \\
\hline 4 & CCA28 & Cerâmica & 11,362 & 9,513 & 1,283 & 133,7 & 0,12 & Disc. & $3,23 \mathrm{~cm}$ & \\
\hline 5 & CCA40 & Lítico & 10,761 & 9,193 & 3,745 & 326,7 & 0,37 & Disc. & \multicolumn{2}{|c|}{ Sem movimento } \\
\hline 6 & CCA24 & Cerâmica & 4,652 & 3,263 & 1,254 & 16,5 & 0,32 & Disc. & $2 \mathrm{~cm}$ & \\
\hline 7 & CCA05 & Lítico & 10,915 & 6,325 & 3,708 & 346,3 & 0,44 & Lam. & $6,9 \mathrm{~cm}$ & \\
\hline 8 & CCA68 & Osso & 8,433 & 1,039 & 0,855 & 6,5 & 0,28 & Acic. & $6,77 \mathrm{~cm}$ & \\
\hline 9 & CCA08 & Lítico & 6,348 & 3,362 & 1,74 & 38,4 & 0,37 & Lam. & \multicolumn{2}{|c|}{ Sem movimento } \\
\hline 10 & CCA35 & Cerâmica & 8,696 & 8,126 & 1,196 & 63,6 & 0,14 & Disc. & \multicolumn{2}{|c|}{ Sem movimento } \\
\hline 11 & CCA74 & Osso & 5,163 & 3,302 & 1,061 & 8,8 & 0,25 & Disc. & $19,13 \mathrm{~cm}$ & \\
\hline 12 & CCA41 & Lítico & 5,728 & 4,175 & 0,711 & 19,9 & 0,14 & Disc. & \multicolumn{2}{|c|}{ Sem movimento } \\
\hline 13 & CCA82 & Concha & 4,33 & 2,103 & 0,677 & 4,6 & 0,22 & Lam. & \multicolumn{2}{|c|}{$\mathrm{x}$} \\
\hline 14 & CCAO2 & Lítico & 14,835 & 5,505 & 3,621 & 428,4 & 0,4 & Acic. & \multicolumn{2}{|l|}{$12,31 \mathrm{~cm}$} \\
\hline 15 & CCA26 & Cerâmica & 12,868 & 10,874 & 1,09 & 178,6 & 0,09 & Disc. & \multicolumn{2}{|l|}{$15,93 \mathrm{~cm}$} \\
\hline 16 & CCA13 & Lítico & 6,755 & 5,788 & 2,485 & 141,5 & 0,39 & Disc. & \multicolumn{2}{|l|}{$17,27 \mathrm{~cm}$} \\
\hline 17 & CCA61 & Concha & 9,4 & 6,016 & 4,904 & 35,5 & 0,65 & Esf. & \multicolumn{2}{|l|}{$x$} \\
\hline 18 & CCA67 & Osso & 7,542 & 0,682 & 0,478 & 2,1 & 0,21 & Acic. & \multicolumn{2}{|l|}{$34,09 \mathrm{~cm}$} \\
\hline 19 & CCA30 & Cerâmica & 10,947 & 5,66 & 1,046 & 81,5 & 0,13 & Lam. & \multicolumn{2}{|l|}{$6,28 \mathrm{~cm}$} \\
\hline 20 & CCA03 & Lítico & 9,004 & 7,608 & 5,095 & 573,7 & 0,61 & Esf. & \multicolumn{2}{|l|}{$37,78 \mathrm{~cm}$} \\
\hline 21 & CCA39 & Cerâmica & 7,707 & 7,703 & 1,073 & 57,3 & 0,13 & Disc. & \multicolumn{2}{|l|}{$6,65 \mathrm{~cm}$} \\
\hline 22 & CCA53 & Lítico & 3,065 & 1,812 & 1,067 & 4,3 & 0,45 & Lam. & \multicolumn{2}{|l|}{$6,47 \mathrm{~cm}$} \\
\hline 23 & CCA64 & Osso & 4,261 & 3,501 & 1,94 & 9,9 & 0,5 & Disc. & $82,03 \mathrm{~cm}$ & \\
\hline 24 & CCA09 & Lítico & 6,547 & 6,247 & 0,979 & 43,7 & 0,15 & Disc. & $3,98 \mathrm{~cm}$ & \\
\hline 25 & CCA80 & Concha & 5,807 & 1,63 & 1,6 & 8,1 & 0,52 & Acic. & $56,19 \mathrm{~cm}$ & \\
\hline 26 & CCA27 & Cerâmica & 12,965 & 2,576 & 1,218 & 106,2 & 0,21 & Lam. & $40,59 \mathrm{~cm}$ & \\
\hline 27 & CCA07 & Lítico & 5,663 & 5,093 & 2,506 & 96,9 & 0,46 & Disc. & $5,51 \mathrm{~cm}$ & \\
\hline 28 & CCA72 & Osso & 8,024 & 2,326 & 1,029 & 20,4 & 0,12 & Lam. & $5,9 \mathrm{~cm}$ & \\
\hline 29 & CCA86 & Osso & 5,407 & 3,876 & 0,817 & 5,7 & 0,17 & Disc. & $10,54 \mathrm{~cm}$ & \\
\hline 30 & CCA23 & Lítico & 5,685 & 2,6 & 1,8 & 32,4 & 0,46 & Acic. & $7,3 \mathrm{~cm}$ & $\rightarrow$ \\
\hline 31 & CCA70 & Osso & 6,839 & 0,709 & 0,7 & 3,2 & 0,31 & Acic. & $22,7 \mathrm{~cm}$ & \\
\hline 32 & CCA21 & Lítico & 5,404 & 4,192 & 3,074 & 88,5 & 064 & Esf. & $5,16 \mathrm{~cm}$ & \\
\hline 33 & CCA33 & Cerâmica & 9,158 & 8,417 & 0,996 & 91,6 & 0,11 & Disc. & $7,9 \mathrm{~cm}$ & $\rightarrow$ \\
\hline 34 & CCA50 & Lítico & 2,958 & 2,139 & 0,711 & 3,3 & 0,28 & Disc. & $6,5 \mathrm{~cm}$ & $\pi$ \\
\hline 35 & CCA52 & Lítico & 3,335 & 2,316 & 1,297 & 6,1 & 0,46 & Disc.. & $5,9 \mathrm{~cm}$ & $\gamma$ \\
\hline 36 & CCA15 & Lítico & 4,542 & 1,235 & 0,839 & 6,5 & 0,35 & Acic. & $13,34 \mathrm{~cm}$ & $\rightarrow$ \\
\hline 37 & CCA34 & Cerâmica & 8,872 & 4,774 & 1,626 & 53,1 & 0,24 & Lam. & $18,38 \mathrm{~cm}$ & \\
\hline 38 & CCA19 & Lítico & 5,223 & 5,128 & 2,64 & 75,6 & 0,51 & Disc. & $6,6 \mathrm{~cm}$ & $\rightarrow$ \\
\hline
\end{tabular}


Tabela 1: Movimentação dos pseudo artefatos no gradeamento da Seção A da UHE Capivari-Cachoeira.

Fonte: Elaborado pela autora com base em Soares (2015). Acic - Acicular; Lam - Lamelar; Disc Discoidal; Esf - Esferoidal. Continuação.

\begin{tabular}{|c|c|c|c|c|c|c|c|c|c|c|}
\hline \multirow{3}{*}{$\begin{array}{c}\text { Posição } \\
\text { na } \\
\text { grade }\end{array}$} & \multirow[t]{3}{*}{ ID } & \multirow[t]{3}{*}{ Tipo } & \multicolumn{3}{|c|}{ Medidas (cm) } & \multirow{3}{*}{$\begin{array}{l}\text { Peso } \\
\text { (gr) }\end{array}$} & \multirow{3}{*}{$\begin{array}{l}\text { Shape } \\
\text { Factor }\end{array}$} & \multirow{3}{*}{$\begin{array}{l}\text { Zingg } \\
\text { (1935) }\end{array}$} & \multirow[t]{3}{*}{ Movimento } & \multirow{3}{*}{$\begin{array}{l}\text { Direção do } \\
\text { Movimento }\end{array}$} \\
\hline & & & $\mathrm{a}$ & b & C & & & & & \\
\hline & & & & & & & & & & \\
\hline 42 & CCA32 & Cerâmica & 9,264 & 5,981 & 1,701 & 71,7 & 0,22 & Disc. & $10,1 \mathrm{~cm}$ & \\
\hline 43 & CCA75 & Osso & 4,514 & 2,723 & 1,196 & 3,6 & 0,34 & Disc. & $24,88 \mathrm{~cm}$ & \\
\hline 44 & CCA84 & Concha & 4,441 & 2,871 & 0,784 & 9 & 0,21 & Disc. & $x$ & \\
\hline 45 & CCA14 & Lítico & 6,834 & 2,288 & 1,072 & 24,1 & 0,27 & Lam. & 9,30 & \\
\hline 46 & CCA69 & Osso & 9,083 & 0,902 & 0,598 & 4,5 & 0,2 & Acic. & $11 \mathrm{~cm}$ & \\
\hline 47 & CCA60 & Concha & 5,477 & 4,775 & 0,717 & 13,3 & 0,14 & Disc. & $79,48 \mathrm{~cm}$ & \\
\hline 48 & CCA83 & Concha & 3,1 & 2,435 & 0,214 & 3,2 & 0,07 & Disc. & $x$ & \\
\hline 49 & CCA81 & Concha & 4,875 & 2,36 & 0,593 & 5,3 & 0,17 & Lam. & $x$ & \\
\hline 50 & CCA76 & Osso & 4,33 & 1,732 & 1,221 & 7,8 & 0,44 & Acic. & $24,74 \mathrm{~cm}$ & \\
\hline 39 & CCA62 & Osso & 3,001 & 2,46 & 1,558 & 6,6 & 0,57 & Esf. & $10,08 \mathrm{~cm}$ & \\
\hline 40 & CCA79 & Concha & 4,485 & 2,274 & 0,723 & 3,3 & 0,22 & Lam. & $x$ & \\
\hline 41 & CCA10 & Lítico & 10,689 & 3,142 & 0,982 & 47,7 & 0,16 & Lam. & $71 \mathrm{~cm}$ & \\
\hline
\end{tabular}

\begin{tabular}{|c|c|c|c|c|c|c|c|c|c|}
\hline (42) & & & 13 & & & $\delta^{52}$ & $0^{15}$ & $2^{14}$ & 69 \\
\hline$c^{59}$ & & & & & 07 & $o^{50}$ & 34 & $\nabla^{84}$ & (60) \\
\hline$y^{66}$ & 68 & $0^{82}$ & & & & & 19 & & $0^{83}$ \\
\hline 1 & $0^{08}$ & (41) & 30 & $0^{53}$ & & (21) & $a^{62}$ & 32 & $0^{81}$ \\
\hline 40 & 35 & $b^{4}$ & 03 & 39 & $0^{23}$ & 70 & $b^{79}$ & & $\sigma^{76}$ \\
\hline
\end{tabular}

Figura 08: Croqui esquemático da distribuição dos materiais no gradeamento inicial, o sombreamento da forma do pseudo artefato. Fonte: SOARES, 2015.

A experimentação com o gradeamento e pseudo-artefatos, ainda sem relatos de aplicação em pesquisas brasileiras, foi importante para demonstrar a variação ocorrida em registros arqueológicos localizados nas margens. Não obstante ao fato dos materiais estarem dispostos fora da matriz, o que facilitaria possíveis movimentações, não ocorreram apenas deslocamentos verticais para cotas mais baixas devido a declividade das encostas (como seria o previsto para materiais líticos, por exemplo), o que evidencia a ação da água no reposicionamento do material. Por sua vez, materiais de baixa densidade, como ossos e conchas, sofrem retrabalhamento e perdas consideráveis por flutuabilidade. 


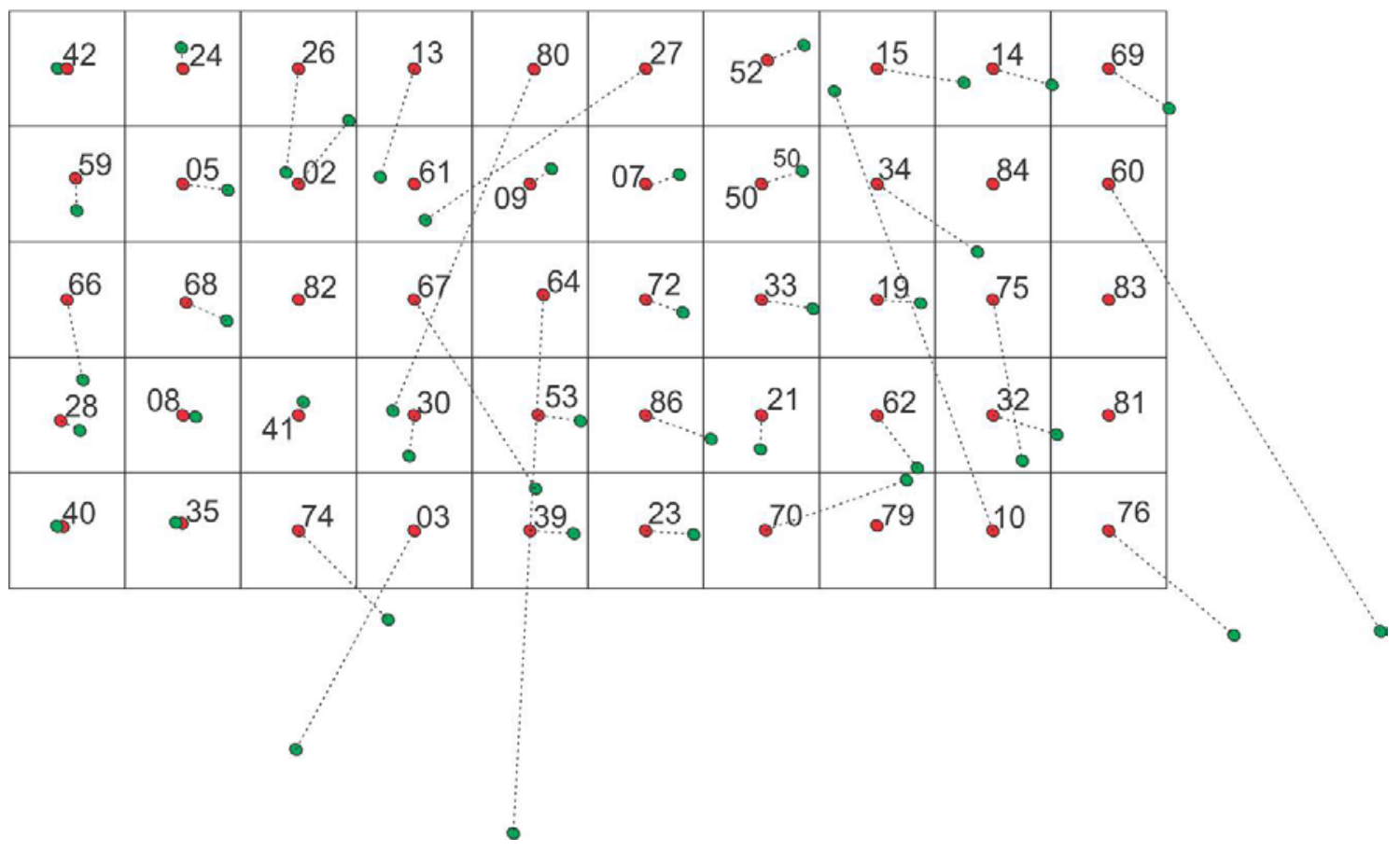

Figura 09: Croqui esquemático da distribuição dos materiais no gradeamento inicial e após a influência da variação do nível do reservatório. Os pontos vermelhos são as posições iniciais do material, e os pontos verdes as posições finais. Fonte: SOARES, 2015.

Em relação a forma dos pseudo artefatos e sua orientação a margem, e consequentemente aos fluxos hidrodinâmicos, a amostragem do experimento não permitem correlações lineares diretas. Entretendo os movimentos de ascensão (subida), foram de poucos centímetros, indicando uma possível adequação do material a micro topografia da margem, e a baixa velocidade de alto do nível do reservatório. Os movimentos de descida, no sentido da linha da água, apresentaram a maior variabilidade de forma e pesos, por se tratar de um plano inclinado e com ação da variação do nível do reservatório este é o movimento mais esperado, em reservatórios com vertentes íngremes estes movimentos seriam ainda mais potencializados. A "perda" da maior parte do material conchifero se deu principalmente pela dificuldade de acesso a parte alagada do reservatório, sua inclinação acentuada, e principalmente da baixa densidade do material que tende a flutuar, especialmente em sistemas de fluxos hidrodinâmico, como no caso aqui retratado.

A confirmação de movimentos contrários à força da gravidade (principalmente para os líticos e cerâmicos), e o deslocamento lateral foram importante elemento de confirmação de alteração do registro arqueológico em sítios as margens de lagos e reservatórios. Outros fatores são os próprios processos erosivos que tendem a desestruturar a matriz pedológica e sedimentar dos sítios arqueológicos, promovendo descaracterização diferencial do potencial informativo desses registros ao longo da faixa de depleção. Os resultados da presente pesquisa evidenciam a necessidade de estudar com mais detalhe os sítios arqueológicos presentes nas futuras faixas de deplecionamento de reservatórios a serem instalados. Por 
serem áreas mais críticas, as faixas previstas de depleção devem ser objeto de mitigação especifica por parte da arqueologia, e em especial, nas áreas que serão atingidas por campos de Fetch mais significativos. Para os casos de reservatórios já licenciados ou sem estudos prévios, as faixas de depleção ainda reservam grande potencial arqueológico sendo, porém necessário, avaliar o grau de integridade e modificação dos registros e, para sítios enterrados, estimativa do volume de matriz sedimentar-arqueológica erodida.

\section{Agradecimentos}

Agradecemos à Universidade Federal do Paraná. Aos membros do Laboratório de Hidrogeomorfologia da Universidade Federal do Paraná pela cooperação em campo e no desenvolvimento da pesquisa. Aos departamentos de Pós-Graduação em Geografia e em Antropologia Social da Universidade Federal do Paraná. À CAPES pela bolsa da autora. 
PROPOSTA DE PROTOCOLO DE GRADEAMENTO PARA MONITORAMENTOS ARQUEOLÓGICOS EM RESERVATÓRIOS DE HIDRELÉTRICAS JÁ INSTALADAS

\section{REFERÊNCIAS BIBLIOGRÁFICAS}

FACCIO, N.B. Os Sítios Arqueológicos Guarani do Município de lepê, estado de São Paulo. R. Museu Arq. Etn., 25: 119-131, 2015

IBAMA - INSTITUTO BRASILEIRO DE MEIO AMBIENTE E DOS RECURSOS NATURAIS RENOVAVEIS. Caderno de formação volume 4: instrumentos da gestão ambiental municipal. Ministério do Meio Ambiente. Brasília, DF: 2006 MMA, Disponível em < http://www.mma.gov.br/estruturas/dai_pnc/_publicacao/76_publicacao19042011110127.pdf>. Acesso em 09 de novembro de 2013.

KASHIMOTO, Emília M. O alto curso do rio Paraná: fronteiras ambientais e arqueológicas. Tese (LivreDocência em Arqueologia) - Museu de Arqueologia/Faculdade de Filosofia, Letras e Ciências Humanas da Universidade de São Paulo, São Paulo, 2007.

KASHIMOTO, Emília M. Fontes arqueológicas que não findam: a relevância do monitoramento arqueológico. Revista Habitus, v. 13, n. 1. 2015.

LACTEC - Instituto de Tecnologia para o Desenvolvimento. Atlas do Potencial Eólico do Paraná. Engenharia Eólica - Camargo e Schubert - LACTEC. Curitiba, 2007. Pg 31 e 32.

MARQUES, M. (2013). Modelagem paramétrica bidimensional para simulação de ondas em águas continentais. Tese de doutorado - Programa de Pós-Graduação Engenharia de Recursos Hídricos e Ambiental. Curitiba: Universidade Federal do Paraná. 219 pp.

MARQUES, M., et al. Estudo comparativo da distribuição do Fetch em reservatórios. XXV CONGRESO LATINOAMERICANO DE HIDRÁULICA SAN JOSÉ, COSTA RICA, 9 AL 12 DE SETIEMBRE DE 2012.

SOARES, M. S. Erosão em margens de reservatório e avaliação geoarqueológica: Estudo da área de depleção da UHE Capivari-Cachoeira PR-Brasil. Dissertação de mestrado. Programa de Pós-Graduação em geografia da Universidade Federal do Paraná. 2015. Disponível em http://acervodigital.ufpr.br/handle/1884/41914

RODRIGUEZ, L. C. E. Monitoramento Florestal: iniciativas, definições e recomendações. Série Técnica IPEF, v.12, n. 31, p.9-22, abril, $1998 . \quad$ Disponível em:<http://www.ipef.br/publicacoes/stecnica/nr31/cap1.pdf>. Acesso em 09 de novembro de 2013.

ROSENHAGEN, A. G. J. Aplicação de uma fórmula de transporte de sedimentos considerando ondas e correntes em um modelo hidro-sedimentológico. Rio de Janeiro: UFRJ/COPPE, 2013.

WILL, R. T.; CLARK, J. A. Stone Artifact Movement on Impoundment Shorelines: A Case Study from Maine. American Antiquity, 61(3), 1996, pp. 499-519. 
ZINGG T. Beiträg zur Schotteranalyse. Schweizerische Mineralogische und Petrographische Mitteilungen, $\mathrm{n}$. 15, pg.39-140. 1935.

Recebido em: 22/09/2017

Aprovado em: 04/12/2017

Publicado em: 24/06/2018
Submited in: 22/09/2017

Aproved in: 04/12/2017

Published in: 24/06/2018 